\title{
Systematic literature review and validity evaluation of the Expanded Disability Status Scale (EDSS) and the Multiple Sclerosis Functional Composite (MSFC) in patients with multiple sclerosis
}

\author{
Sandra Meyer-Moock ${ }^{1 *}$, You-Shan Feng $^{1}$, Mathias Maeurer ${ }^{2}$, Franz-Werner Dippel ${ }^{3}$ and Thomas Kohlmann ${ }^{1}$
}

\begin{abstract}
Background: There are a number of instruments that describe severity and progression of multiple sclerosis and they are increasingly used as endpoints to assess the effectiveness of therapeutic interventions. We examined to what extent the psychometric properties of two accepted instruments - EDSS and MSFC - meet methodological standards and the value they have in clinical trials.

Methods: We conducted a systematic literature search in relevant databases [MEDLINE (PubMed), ISI Web of Science, EMBASE, PsycINFO \& PSYNDEX, CINAHL] yielding 3,860 results. Relevant full-text publications were identified using abstract and then full-text reviews, and the literature was reviewed.

Results: For evaluation of psychometric properties (validity, reliability, sensitivity of change) of EDSS and MSFC, 120 relevant full-text publications were identified, 54 of them assessed the EDSS, 26 the MSFC and 40 included both instruments. The EDSS has some documented weaknesses in reliability and sensitivity to change. The main limitations of the MSFC are learning effects and the z-scores method used to calculate the total score. However, the methodological criterion of validity applies sufficiently for both instruments.

For use in clinical studies, we found the EDSS to be preferred as a primary and secondary outcome measure in recent studies (50 EDSS, 9 MSFC).

Conclusions: Recognizing their strengths and weaknesses, both EDSS and MSFC are suitable to detect the effectiveness of clinical interventions and to monitor disease progression. Almost all publications identify the EDSS as the most widely used tool to measure disease outcomes in clinical trials. Despite some limitations, both instruments are accepted as endpoints and neither are discussed as surrogate parameters in identified publications. A great advantage of the EDSS is its international acceptance (e.g. by EMA) as a primary endpoint in clinical trials and its broad use in trials, enabling cross-study comparisons.
\end{abstract}

Keywords: Multiple sclerosis, Expanded Disability Status Scale (EDSS), Multiple Sclerosis Functional Composite (MSFC), Psychometric properties, Validity, Reliability, Sensitivity of change

\footnotetext{
* Correspondence: sandra.meyer-moock@uni-greifswald.de

'Institute for Community Medicine, University Medicine Greifswald,

Walther-Rathenau-Strasse 48, 17475 Greifswald, Germany

Full list of author information is available at the end of the article
} 


\section{Background}

Multiple sclerosis (MS) is a chronic inflammatory disease of the central nervous system that mainly affects young adults. The disease is characterized by the occurrence of relapsing neurological deficits that affect different functional systems of the central nervous system. The majority of patients initially present with a relapsing remitting disease course (RRMS $>80 \%$ ), however after $10-15$ years about $60 \%$ of these patients show a transition into a secondary progressive disease course (SPMS) that is characterized by a gradual decline of neurological function. In less than $15 \%$ of cases, the disease course is progressive from the onset (primary progressive MS, PPMS) [1].

In recent decades, a number of instruments have been developed that describe the clinical severity and the functional deficits in multiple sclerosis. These instruments are increasingly used as an endpoint in clinical trials to assess the effectiveness of therapeutic interventions.

The most popular and widely used instrument is the Expanded Disability Status Scale (EDSS) of Kurtzke [2]. The EDSS is a clinician-administered assessment scale evaluating the functional systems of the central nervous system. The EDSS is used to describe disease progression in patients with MS and to assess the effectiveness of therapeutic interventions in clinical trials. It consists of ordinal rating system ranging from 0 (normal neurological status) to 10 (death due to MS) in 0.5 increments interval (when reaching EDSS 1). The lower scale values of the EDSS measure impairments based on the neurological examination, while the upper range of the scale (> EDSS 6) measures handicaps of patients with MS. The determination of EDSS $4-6$ is heavily dependent on aspects of walking ability.

Another important instrument is the Multiple Sclerosis Functional Composite (MSFC) [3], which was developed by the MS Society's Clinical Assessment Task Force [4] as an additional clinical measure of MS disability progression. The primary goal for creating the MSFC was to improve the standard measure of MS disability for clinical trials and to develop a multidimensional metric of overall MS clinical status [4]. The MSFC is a three-part performance scale for evaluating the degree of impairment in MS patients. It includes the assessment of leg function by moving a short walking distance ("Timed 25-Foot Walk", T25FT), the assessment of arm function using breadboard test ("9-Hole Peg Test", 9HPT) and an attention/concentration test to assess cognitive functions ("Paced Auditory Serial Addition test”, PASAT). An integrated MSFC score is calculated using z-scores. There is an ongoing debate about which dimensions to include in the MSFC (e.g. the inclusion of a vision testing) as well as how the reference population affect the standardized scoring (z-scores) of the MSFC [5-13]. In recent years, the MSFC is increasingly used in clinical trials.
A number of other instruments are available to assess MS: the Ambulation Index (AI) [14], the Scripps Neurological Rating Scale (SNRS) [15] and the Illness Severity Scale (ISS) [16], the Guy's Neurological Disability Scale (GNDS) [17] and the Multiple Sclerosis Impairment Scale (MSIS) [18]. Furthermore, the overall Functional Independence Measure (FIM) [19] and the Cambridge Multiple Sclerosis Basic Score (CAMBS) [20] are clinical assessment instruments that could be used to assess MS [21]. Specific instruments for measuring health-related quality of life in MS patients are the Multiple Sclerosis Quality of Life-54 (MSQOL-54) [22] and the Multiple Sclerosis Quality of Life Inventory (MSQLI) [23]. Only a few of these instruments meet the requirements of methodological standards (e.g. validity, reliability, responsiveness), particularly for use in clinical trials. None of these instruments is recognized to use in clinical trials without any restrictions.

The aim of this study was to identify strengths and weaknesses of EDSS and MSFC. We investigated to what extent the psychometric properties of the two most important instruments - EDSS and MSFC - meet the methodological standards and what value they have in clinical trials. Although different methodological characteristics of the EDSS are the focus of many studies, a summary and synthesis of the study results is missing. In addition, the importance the MSFC is still a matter of debate and a summary of its methodological characteristics is also missing. We addressed this gap by conducting a systematic literature review to specifically answer the following questions:

- Are the instruments suitable to detect the efficacy and/or effectiveness of clinical interventions and to monitor the disease progress?

- Do the methodological properties of EDSS and MSFC meet the required standards of objectivity, reliability and validity as applied to instruments for assessment of disease impact in MS?

- What is the evidence of the practicality and sensitivity to change of these instruments?

- Which methodological shortcomings of EDSS and MSFC must be considered in interpretation of study results?

- Which minimally important difference (minimal clinically important difference, MCID) is reported for EDSS and MSFC?

\section{Methods}

The study was conducted in two phases. First, an exploratory electronic literature search was undertaken to (a) develop and optimize a systematic search strategy and (b) estimate the extent and quality of available studies. Then, a systematic literature search was conducted using the 
developed search algorithms. The databases MEDLINE (PubMed), ISI Web of Science, EMBASE, PsycINFO and CINAHL \& PSYNDEX were systematically searched. Search terms were: Multiple Sclerosis + Expanded Disability Status Scale OR EDSS (for EDSS) and Multiple Sclerosis + Multiple Sclerosis Functional Composite OR MSFC (for MSFC) (Table 1).

Overall, 3680 results were identified (4272 of the initially generated 8132 hits were excluded as duplicates); the abstracts were reviewed by two independent scientists and structured according to the following criteria:

1) Psychometric studies: validity, reliability, sensitivity of change, head-to-head comparisons, further developments of EDSS or MSFC and reviews.

2) Publications on clinical trials in which the EDSS and/or the MSFC is used as outcome measure or part of it.

3) Other types of studies, if these relate to the central question (for example, review articles).

When the theme did not meet the research question, the abstract was excluded. A total of 684 publications were classified as relevant and ordered as full-text publications in electronic copy or selected in lending (psychometric publications $\mathrm{n}=295$; papers on clinical studies $\mathrm{n}=364$; reviews, summaries etc. $\mathrm{n}=25$ ).

In a further selection process the full-text psychometric papers $(n=295)$ were reviewed and subdivided into:

1) Studies that include information about the psychometric properties of the investigated scores (validity, reliability, sensitivity to change, and head-to-head comparisons).

2) Studies that focus on a different instrument than EDSS and/or MSFC (without acceptable psychometric information about the EDSS or MSFC).

3) Studies that are not relevant to the central study questions.

The categories 2 and 3 were excluded. Ultimately, 120 papers were identified as relevant methodological publications. Figure 1 gives an overview of the selection process.
In addition, the publications on clinical trials were reviewed. Furthermore, the public register of clinical trials ClinicalTrials.gov by the U.S. National Institutes of Health was systematically searched and an overview of relevant clinical studies generated.

\section{Results}

We identified 120 publications with methodological content for EDSS and/or MSFC. Table 2 gives an overview of scores distribution and period of publication.

Numerous relevant studies of EDSS were published before 2000 [24-32]. The majority of the MSFC studies as well as the head-to-head comparisons were published between the years 2000 and 2009.

\section{Development of EDSS and MSFC as endpoint in clinical trials} In the early clinical studies evaluating therapeutic interventions for MS, the effectiveness of treatment was exclusively measured by reducing the number of relapses, due to the importance of relapses for disease progression [33-38]. However disease progression measured by EDSS was introduced as a primary endpoint in 1996 when the therapeutic effect of Interferon-beta 1a i.m. was evaluated. Currently, progression of disability measured by EDSS is the most important secondary endpoint in MS trials addressing RRMS patients and the most important primary endpoint in all studies dealing with therapeutic interventions in patient with a progressive disease course. Recent studies usually also include the MSFC-score as an endpoint in clinical trials [39-41].

Therefore the current guidelines of the European Medicines Agency (EMA) [42] recommend prevention and delay of disability progression for SPMS and PPMS studies and relapses, disease progression and the increase in disability for studies on RRMS or SPMS (with superimposed relapses) as primary or secondary endpoints.

\section{Psychometric properties of EDSS and MSFC EDSS}

Overall, we identified 54 full-text publications in which the psychometric properties of the EDSS (without comparison to the MSFC) were examined. One of the studies is the original work of Kurtzke [2], 9 were summary

Table 1 Results of systematic literature research*

\begin{tabular}{lcccc}
\hline & EDSS & MSFC & EDSS or MSFC & EDSS and MSFC \\
\hline MEDLINE (PubMed) (all limits) & 1814 & 164 & 1863 & 115 \\
ISI Web of Science (limit language) & 2358 & 384 & 2543 & 208 \\
EMBASE (all limits) & 1890 & 148 & 1932 & 106 \\
PsycINFO \& PSYNDEX (limits humans, adult) & 1282 & 79 & 1294 & 67 \\
CINAHL (limit humans, adult) & 504 & 41 & 510 & 35 \\
\hline
\end{tabular}

*According to database limitations, the search was specified by additional search criteria: 1) humans, 2) adult (>18 years old), 3) language (English, German, French, Spanish). 


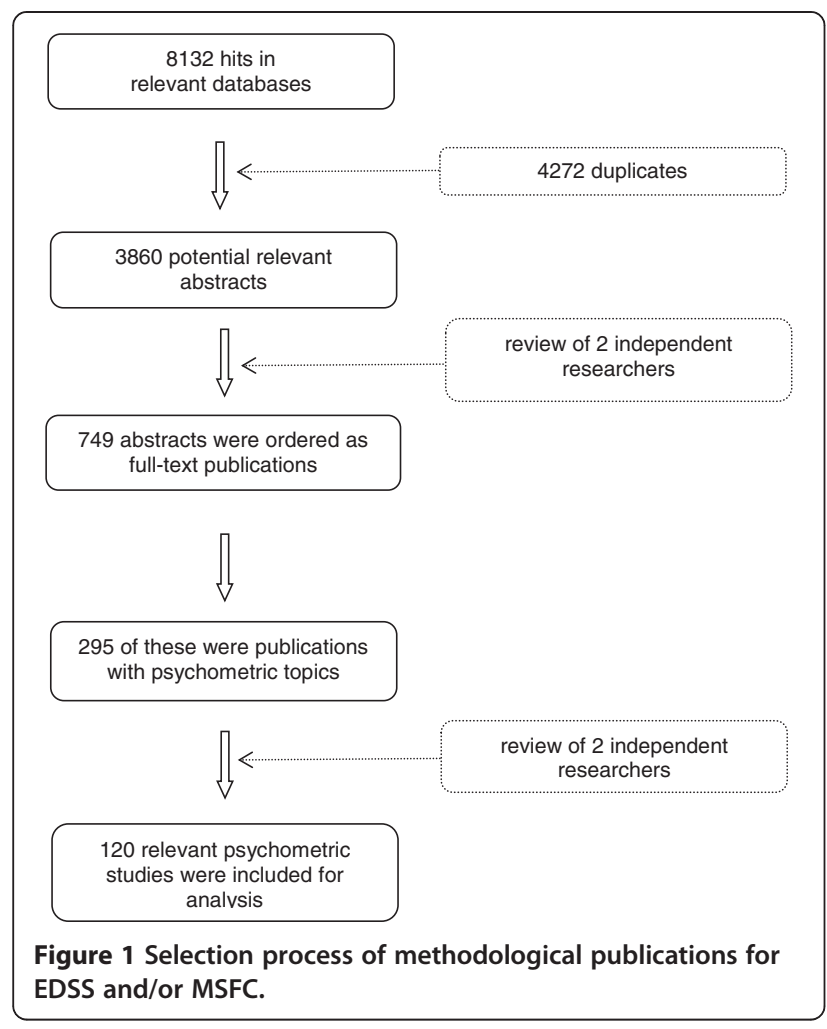

papers or reviews, 21 investigated the validity, 13 the reliability, 8 the sensitivity of change and 10 included modifications of the EDSS, especially versions for selfreporting. In addition, there is a simulation study on power (overlaps are possible). (The 40 studies which consider the MSFC as well are not listed here; for more information see MSFC.)

Kurtzke himself did not test the psychometric properties of EDSS. A series of studies on the properties and the functional systems of the EDSS was conducted as awareness of psychometric methods increased [24-29,32,43-45]. Most of the early studies concentrated on reliability. A first study considering reliability, validity and sensitivity to change is the work of Sharrack and colleagues [29]. A

Table 2 Psychometric publications classified by score and year

\begin{tabular}{lcccc}
\hline Score & \multicolumn{3}{c}{ Year of publication } & \\
\cline { 2 - 4 } & Up to $\mathbf{1 9 9 9}$ & $\mathbf{2 0 0 0 - 2 0 0 9}$ & Since $\mathbf{2 0 1 0}$ & Total \\
\hline EDSS & 29 & 19 & 6 & 54 \\
MSFC $^{*}$ & 3 & 19 & 4 & 26 \\
EDSS + MSFC* ** & 2 & 33 & 5 & 40 \\
$\quad$ Head-to-head- & - & 11 & 1 & 12 \\
$\quad$ comparisons & & & & \\
Total & & & & 120 \\
\hline
\end{tabular}

*Some studies deal only with parts of the MSFC (T25FW, 9HPT, PASAT). **This includes although publications that examine other instruments besides EDSS and MSFC. detailed study on the validity, reliability (inter-and intrarater reliability), sensitivity to change, and floor and ceiling effects on a sample of patients with MS is published from Hobart and colleagues in 2002 [32].

Validity The validity of the EDSS has been established in numerous studies: Amato and colleagues [31] certify a good validity of the EDSS; Ebers [46] described the EDSS as "well validated". In early studies, the EDSS was correlated with the Barthel Index (BI), the London Handicap Scale (LHS), the Scripps Neurological Rating Scale (SNRS), the Functional Independence Measure (FIM) [47] and physical function ability of the SF-36; strong to very strong correlation could be shown $[29,32,48]$, weaker results were reported between the EDSS and the ambulation index (AI) $[17,49]$. In addition, the EDSS correlated with neuropsychological impairment and brain changes measured by MRI - with no or weak correlations [50]. Results of correlations of EDSS with patient-reported outcomes were heterogeneous, from moderate to no correlation.

In studies checking the validity of the MSFC, the EDSS is often used as gold standard reference (see the validity of the MSFC in the next section).

Reliability A criticism of several studies is the limited reliability of EDSS measurements [24,25,27,44,51]. For inter-rater reliability kappa values between 0.32 to 0.76 for the EDSS and between 0.23 to 0.58 for the individual functional systems were reported $[24,25,27,44,52]$. The intra-rater agreement is slightly higher than the interrater, they both show greater variability for lower EDSS scores (1.0-3.5) than for higher score values [27,53].

Different intervals of agreement (exact match, one step (0.5 points), two steps (1.0 points), etc. on the EDSS scale) affect the degree of reliability; studies that attest good reproducibility to the EDSS allow higher deviations. From a deviation of 3 steps on the EDSS scale (1.5 points) almost all studies report good to perfect inter-rater reliability.

Sensitivity to change In the literature review, the EDSS was found somewhat sensitive to changes in disease progression [17,54]. Schwid and colleagues [55] compared limitations of walking ability in MS patients, the EDSS and Ambulation Index and found them to be less sensitive to change than the Dmax (the maximum distance that a person can go) and T8 (time to walk $8 \mathrm{~m}$ ). Similarly, Vaney and colleagues [56] reported lesser changes in EDSS than in the Rivermead Mobility Index (RMI), the $\mathrm{AI}$ and the $10 \mathrm{~m}$ walking time test. Hohol and colleagues [53] reported a lower sensitivity to change in EDSS compared with Disease Steps. In turn, Koziol and colleagues [57] observed in a clinical study that the EDSS and the Scripps Neurological Rating Scale could 
reflect improvements in the cladribine group and deteriorations in the placebo group appropriately.

Moreover, some studies showed that the rates of change varied depending on the initial value. Greater rates of change were observed for minor severity of disease, but from an EDSS score of 6, the EDSS showed very little change in sensitivity [58]. Ravnborg and colleagues [59] reported higher annual rates of change (worsening health) at low EDSS baseline.

Feasibility, scale- and distribution properties The EDSS shows a bimodal frequency distribution in a number of studies $[29,30,54,57]$ with only a few values in the central region and two peaks around the values 3 and 6 [31,53,59].

In numerous studies the unequal interval distances between the EDSS have been criticized, [31,54,60], particularly in the context of clinical trials. This leads to different meanings of change depending on the position on the scale: a difference between the values 1.0 and 2.0 has a different relevance as between 6.0 and 7.0 [61]. Amato and Ponziani [31] as well as Drulovic and colleagues [62] criticized that the use of parametric statistical methods is not possible. The EDSS is also not suitable for use in economic analyses [63]. The non-linearity was demonstrated in studies comparing the EDSS with the health-related quality of life $[22,64]$.

As reported in the literature, the lower scale values (0-4.0) are influenced by impairments detected by the neurological exam of eight functional systems, while the values above 4.0 are mainly based on the walking ability, and values above 6 mainly on patients handicaps $[56,62]$.

Interpretation and comparability A clear recommendation how to interpret changes in EDSS-values cannot be found in the literature. Noseworthy et al. [24] recommend a progression of 1.0 as a meaningful change in clinical trials. Similarly, Healy and colleagues [65] recommended using a continuing progression by one unit on the scale for at least 6 or 12 months. On the other hand, Francis et al. [25] suggested a change of 1.5 points to be more appropriate. For patients with an EDSS of 5.5 or higher at inclusion in the study, progression by 0.5 was deemed sufficient, since changes in this range of the scale are easily perceptible [66].

The guidelines of the European Medicines Agency (EMA) [42] suggest that an average change from baseline is not an adequate efficacy parameter. Instead, they recommend defining treatment success or treatment failure of either reaching a certain EDSS score or a sustained change in sufficient volume. A separate consideration of the lower and upper value range of the EDSS is recommended: 1 point on the EDSS scale with a baseline
EDSS score less than or equal to 5.5 and 0.5 points in an EDSS score over 5.5.

A commonly recognized benefit of the EDSS is its good comparability of results from different studies $[31,42,63]$. The EDSS is fairly robust for measurements over a long period $[46,62]$.

\section{MSFC}

Overall, we identified 66 full-text publications in which the psychometric properties of the MSFC are reported. Of these, 10 were reviews or summaries, 14 examined the validity, 18 the sensitivity to change and 4 the reliability. Seven publications included modifications to the MSFC. A total of 40 publications also contain information on the EDSS with two publications assessing the superiority of the MSFC over the EDSS [3,4] (overlaps are possible).

Validity MSFC has been shown to correlate with other indicators of disease in MS, including the EDSS, MRI measures (although correlation here is weak) $[67,68]$, patient reported health [69-71] and employment [3,5,72-74]. The predictive validity of MSFC has also been shown for EDSS, brain atrophy, SPMS disease and self-reported health [74].

The EDSS is used most often to test the validity of the MSFC - studies found strong correlations between the two scores, ranging from -0.41 to -0.83 [3,71,75-77]. The PASAT is the weakest correlate [3]. Kalkers and collegues [78] found that while overall MSFC scores distinguished across MS disabilities, the PASAT could not distinguish as well. In fact, Brochet et al. [67] found no correlation between PASAT and EDSS. Rudick and collogues [9] found that MSFC progression seem to be driven by one component of the MSFC, the Timed 25-Foot Walk (T25FWT).

Correlation with MRI measures $[67,68]$ and patient reported outcomes [69-71] were inconsistent, showing moderate to no correlations. For example, MSFC was correlated with the physical component of the SF-36 scale and the sickness impact profile, but not with the mental component of the SF-36 [70]. Change in MSFC score also is shown to have a very weak correlation with change in SF-36 score [79].

Reliability The source publication [4] found MSFC reliability to be high (intra-rater $\mathrm{ICC}=0.98$, inter-rater $\mathrm{ICC}=0.96$ ). Inter-rater and intra-rater reliability were shown to be high for MSFC overall score as well as its component measures. The intraclass correlation (ICCs) were above 0.8 across studies $[4,52,78,80]$. Schwid and colleges [81] found that MSFC scores varied over measurement periods (over 5 days) but all within 20\% change in raw scores. 
However, the 9HPT and PASAT have well demonstrated practice effects, meaning that as participants learn about the test, their scores improve $[4,52,80,82,83]$. This is a general problem of all studies that follow patients over time. The MSFC manual suggests administering the PASAT at least three times prior to baseline measurement to address this practice effect as there is some evidence that practice effects stabilized by the 4 th observation $[73,75]$. However, some evidence point to practice effect persisting beyond fourth testing repeats [83].

Some studies did not detect notable practice effects $[71,84,85]$. However, due to potential artifacts that may lead to overestimations of improvement in MSFC scores, precautions should be taken during data collection.

Sensitivity to change In the source database [4], MSFC was found to significantly decline from baseline $(z=-0.14)$ to 2 years $(z=-0.14)$ for patients in placebo groups of clinical trials. They also found patients with MSFC deteriorating by at least one standard deviation to have an odds ratio of 2.1 for sustained EDSS deterioration $[3,4]$.

Some studies indicate the MSFC to be more sensitive than EDSS to detecting changes in disease [71,84-86]. However, due to missing dimensions (e.g visual function) there is also evidence that the MSFC is not more sensitive than the EDSS [73,77]. Others found the PASAT does not reflect disease progression in certain MS populations [11 for PPMS].

Feasibility Fischer et al. [4] found that it took 15 minutes for trained personnel to administer the MSFC to patients (using a small sample of 10 patients). The PASAT, however, is notoriously disliked by patients [73]. From our review, some studies found patients not willing to undergo the PASAT [76,87].

Interpretability A major drawback of the MSFC is its interpretability, especially in the scoring mechanism. Although choice of reference population does not affect statistical significance [4], it does change the value of the z-scores, making cross-trial comparison problematic. Some studies examined reference population choice on MSFC scores $[10,78,88]$ and found the question of reference population problematic.

A further objection to $\mathrm{z}$-score interpretability is its abstractness from clinically meaningful values. A solution involves using clinically relevant cut-offs in the raw scores of MSFC dimensions as opposed to z-scores. Bosma et al. [82] found optimal cutoff values to be $20 \%$ change for the T25FW and 20\% for the 9HPT but could not determine a relevant cutoff for PASAT. Hoogervorst et al. [69] established that 20\% change in all three MSFC measures were meaningful to patient's own perception of health (using the GNDS as a reference measure). Similarly, other studies found the $20 \%$ change in T25FW $[89,90]$ and 9HPT [90] reflect disease status in MS patients. Rudick et al. [9] further found, using data from the AFFRIM and SENTINEL trials, that a 15 or $20 \%$ change, sustained for 3 months, seems to be an adequate way to quantify the MSFC dimensions. However, others found the $20 \%$ not sufficient to detect neurological worsening [81].

\section{Use of EDSS and MSFC in Clinical Trials}

In addition to the review, a systematic search in the public register of clinical trials ClinicalTrials.gov by the U.S. National Institutes of Health was conducted to identify relevant clinical trials for MS. Under the topic multiple sclerosis (search terms) 904 studies were identified. In a second step, clinical phase III or IV studies on interferon beta-1b, interferon beta-1a, glatiramer acetate, fingolimod, natalizumab, mitoxantrone and cyclophosphamide as well as - due to their current importance - studies on laquinimod, teriflunomide, BG-12 and alemtuzumab were extracted. Finally, 66 clinical phase III or IV studies to a relevant agent of MS therapy could be identified. In 50 of those studies EDSS and/or MSFC were used as primary and/or secondary outcome measurement method (in 15 studies EDSS/MSFC were not reported, in 1 study EDSS was named as a tertiary endpoint). In 9 of the 50 relevant studies the MSFC was used in addition to the EDSS, but there is no study that used only the MSFC (Table 3). It was found that the EDSS has been used preferentially as primary and secondary outcome measurement.

\section{Discussion}

This study examined the extent to which the psychometric properties of the most important instruments to assess disease progression in MS - EDSS and MSFC - meet the methodological standards and what value they have as outcome measures in clinical trials.

Table 3 EDSS and MSFC as primary or secondary outcome in relevant clinical trials*

\begin{tabular}{lccc}
\hline & \multicolumn{2}{c}{ Start of study } & \\
\cline { 2 - 4 } & $\mathbf{1 9 9 0 - \mathbf { 2 0 0 0 }}$ & $\mathbf{2 0 0 0}$ - today & Total \\
\hline EDSS & 13 & 37 & 50 \\
Primary outcome & 10 & 17 & 27 \\
Secondary outcome & 3 & 20 & 23 \\
MSFC & - & 9 & 9 \\
Primary outcome & - & 1 & 1 \\
Secondary outcome & - & 8 & 8 \\
\hline
\end{tabular}

*Not taken into account is that the EDSS is in addition to the primary outcome used as secondary outcome. In this overview, only a classification in the "higher" endpoint occurs. 
In a systematic literature review of 120 relevant fulltext publications, we found that while the EDSS is the most widely used instrument in clinical trials assessing the effectiveness of therapeutic interventions, the MSFC is becoming increasingly important.

Single methodological characteristics of the two instruments have been investigated in numerous studies. The EDSS has some documented weaknesses in reliability and sensitivity to change. Although the MSFC was developed rigorously, its weaknesses include interpreting the $\mathrm{z}$-scores (which are used to calculate the summary score from the three components), the learning effects of the PASAT, low acceptance by patients and lack of a visual dimension. However, the MSFC has better sensitivity and reliability compared to EDSS. The methodological quality criterion of validity is sufficiently met by both instruments.

Despite the criticisms, in particular the EDSS could be classified as an important endpoint. In neither publication, the EDSS (or MSFC) are discussed as a surrogate parameter (in contrast to MRI measurements). Cohen et al. [73] emphasized in their review of clinical outcome parameters, the general acceptance of the EDSS as an endpoint by different authorities. In contrast, the MSFC is usually used as a secondary endpoint.

The importance of the instruments is also reflected in our evaluation of clinical trials: in 50 of 66 identified relevant phase-III and phase-IV studies, disease progression as measured by EDSS was used as primary (27 studies) or secondary outcome (23 studies). The MSFC was used in eight studies as a secondary endpoint and only one study as a primary endpoint.

In summary, both instruments are acceptable outcome criteria to assess the effectiveness of clinical interventions and to monitor disease progression. When using the EDSS, its limited inter-and intra-rater reliability should be considered. All possibilities to increase reliability should be used, including training of investigators, assessment by the same doctor/neurologist during the study, specified times of detection, standardized protocols for neurological examination and a precise definition of all requirements. When using the MSFC, the learning effects of the PASAT and 9HPT should be considered and controlled (e.g. using control groups).

Concerning the natural history of MS, Weinshenker and colleagues [1] observed an average change of 0.5 points on the EDSS scale in a year. A clear recommendation on interpreting changes in EDSS and MSFC values does not yet exist. EDSS changes by 1.0 points from a baseline EDSS less than or equal to 5.5 and 0.5 points over a baseline 5.5 are commonly recognized as a clinically increase in disability. However, it is now understood that it is more accurate to define disability change as a sustained change for 12 weeks or, even more reliably, for 24 weeks.

For the MSFC, changes by $20 \%$ in the individual components are considered to be clinically relevant. However, it is difficult for a clinician to understand what a $20 \%$ change in MSFC subscores is while a significant EDSS change is more intuitively understood.

Overall, the literature reveals that the EDSS is the most widely used and best-known instrument to assess disease progression in MS. The advantages and disadvantages of EDSS and MSFC have been investigated frequently. The great advantage of the EDSS is its international acceptance (including the EMA) as a primary endpoint in clinical trials. Because it is so commonly used, studies that use the EDSS can easily compare results to other findings. Following the current literature, we can conclude that the importance of the EDSS will be unabated in future. Major changes of the EDSS are not recommended, as not to jeopardize its advantage.

In addition, the use of other measurements as clinical trial endpoints (e.g. the MSFC) is recommended to provide information on dimensions no covered in the EDSS, such as upper limb function or cognitive skills.

\section{Conclusions}

The assessment instruments we examined, EDSS and MSFC, both are frequently and internationally used in clinical studies - despite their well know methodological limitations. They are suitable to detect patient-relevant endpoints in MS with reasonable validity in spite of some methodological concerns.

\section{Consent}

Written informed consent was obtained from the patients for the publication of the reviewed studies and accompanying images.

\section{Competing interests}

The authors declare that they have no competing interests.

\section{Authors' contributions}

SMM conducted the literature review and drafted the manuscript. YSF conducted the literature review and drafted the manuscript. MM drafted the manuscript and gave clinical input. FWD contributed to the clinical studies section and drafted the manuscript. TK conceptualized the study and critically reviewed the manuscript. All authors read and approved the final manuscript.

\section{Author details}

${ }^{1}$ Institute for Community Medicine, University Medicine Greifswald, Walther-Rathenau-Strasse 48, 17475 Greifswald, Germany. ${ }^{2}$ Department of Neurology, Caritas Krankenhaus, Bad Mergentheim, Germany. ${ }^{3}$ Department of Internal Medicine, Neurology and Dermatology, University of Leipzig, Leipzig, Germany.

Received: 21 November 2013 Accepted: 17 March 2014 Published: 25 March 2014 


\section{References}

1. Weinshenker BG: The natural history of multiple sclerosis. Clin Neurol Neurosurg 1995, 13:119-146.

2. Kurtzke JF: Rating neurologic impairment in multiple sclerosis: an expanded disability status scale. Neurology 1983, 5:580-583.

3. Cutter GR, Baier ML, Rudick RA, Cookfair DL, Fischer JS, Petkau J, Syndulko K, Weinshenker BG, Antel JP, Confavreux C, Ellison GM, Lublin F, Miller AE, Rao SM, Reingold S, Thompson A, Willoughby A: Development of a multiple sclerosis functional composite as a clinical trial outcome measure. Brain 1999, 122:871-882.

4. Fischer JS, Rudick RA, Cutter GR, Reingold SC: The Multiple Sclerosis Functional Composite Measure (MSFC): an integrated approach to MS clinical outcome. National MS Society Clinical Outcomes Assessment Task Force. Mult Scler 1999, 5(4):244-250.

5. Baier ML, Cutter GR, Ruck RA: Low-contrast letter acuity testing captures visual dysfunction in patients with multiple sclerosis. Neurology 2005, 64:992-995.

6. Balcer $\mathrm{L}$ : Clinical outcome measures for research in multiple sclerosis. J Neuroophthalmol 2001, 21:296-301.

7. Balcer LJ, Baier ML, Cohen JA, Kooijmans MF, Sandrock AW, Nano-Schiavi ML, Pfohl DC, Mills M, Bowen J, Ford C, Heidenreich FR, Jacobs DA, Markowitz CE, Stuart WH, Ying GS, Galetta SL, Maguire MG, Cutter GR: Contrast letter acuity as a visual component for the multiple sclerosis functional composite. Neurology 2003, 61:1367-1373.

8. Drake AS, Weinstock-Guttman B, Morrow SA, Hojnacki D, Munschauer FE, Benedict RH: Psychometrics and normative data for the multiple sclerosis functional composite: replacing the PASAT with the symbol digit modalities test. Mult Scler 2010, 16:228-237.

9. Rudick RA, Polman CH, Cohen JA, Walton MK, Miller AE, Confavreux C, Lublin FD, Hutchinson M, O'Connor PW, Schwid SR, Balcer LJ, Lynn F, Panzara MA, Sandrock AW: Assessing disability progression with the multiple sclerosis functional composite. Mult Scler 2009, 15:984-997.

10. Uitdehaag BMJ, Adèr HJ, Roosma TJ, de Groot V, Kalkers NF, Polman CH: Multiple sclerosis functional composite: impact of reference population and interpretation of changes. Mult Scler 2002, 8:366-371.

11. Bosma L, Kragt JJ, Brieva L, Khaleel Z: The search for responsive clinical endpoints in primary progressive multiple sclerosis. Mult Scler 2009, 15:715-720.

12. Vaney C, Vaney S, Wade DT: SaGAS, the short and graphic ability score: an alternative scoring method for the motor components of the multiple sclerosis functional composite. Mult Scler 2004, 10:231-242.

13. Nagels $G$, Geentjens $L$, Kos D, Vleugels L, D'hooghe MB, Van Asch P, Vuylsteke K, De Deyn PP: Paced visual serial addition test in multiple sclerosis. Clin Neurol Neurosurg 2005, 107:218-222.

14. Hauser SL, Dawson DM, Lehrich JR, Beal MF, Kevy SV, Propper RD, Mills JA, Weiner HL: Intensive immunosuppression in progressive multiple sclerosis: a randomized, three-arm study of high-dose intravenous cyclophosphamide, plasma exchange, and ACTH. N Engl J Med 1983, 308:173-180.

15. Sipe JC, Knobler RL, Braheny SL, Rice GP, Panitch HS, Oldstone MS: A neurologic rating scale (NRS) for use in multiple sclerosis. Neurology 1984, 34:1368-1372

16. Mickey MR, Ellison GW, Myers LW: An illness severity score for multiple sclerosis. Neurology 1984, 34:1343-1347.

17. Sharrack B, Hughes R: The Guy's Neurological Disability Scale (GNDS): a new disability measure for multiple sclerosis. Mult Scler 1999, 5(4):223-233.

18. Ravnborg M, Grønbech-Jensen M, Jønsson A: The MS-impairment scale: a pragmatic approach to the assessment of impairment in patients with multiple sclerosis. Mult Scler 1997, 3:31-42.

19. Hamilton BB, Granger CV, Shervin FS, Zielezny M, Teshman JS: A uniform national data system for medical rehabilitation. In Rehabilitation Outcomes: Analysis and Measurements. Edited by Fuhrer MJ. Baltimore: Brookes; 1987:137-147.

20. Mumford CJ, Compston A: Problem with rating scales for multiple sclerosis: a novel approach - the CAMBS score. J Neurol 1993, 240:209-215.

21. Noseworthy JH: Clinical scoring methods for multiple sclerosis. Ann Neurol 1994, 36(Supplement):S80-S85.

22. Vickrey BG, Hays RD, Harooni R, Myers LW, Ellison GW: A health-related quality of life measure for multiple sclerosis. Qual Life Res 1995, 4:187-206.
23. Ritvo PG, Fischer JS, Miller DM, Andrews H, Paty DW, LaRocca MG: Multiple Sclerosis Quality of Life Inventory (MSQLI): a user's Manual. New York: National Multiple Sclerosis Society; 1997

24. Noseworthy JH, Vandervoort MK, Wong CJ, Ebers GC: Interrater variability with the Expanded Disability Status Scale (EDSS) and Functional Systems (FS) in a multiple sclerosis clinical. Neurology 1990, 40:971-975.

25. Francis DA, Bain P, Swan AV, Hughes RA: An assessment of disability rating scales used in multiple sclerosis. Arch Neurol 1991, 48:299-301.

26. Verdier-Taillefer MH, Zuber M, Lyon-Caen O, Clanet M, Gout O, Louis C, Alpérovitch A: Observer disagreement in rating neurologic impairment in multiple sclerosis: facts and consequences. Eur Neurol 1991, 31:117-119.

27. Goodkin DE, Cookfair D, Wende K, Bourdette D, Pullicino P, Scherokman B, Whitham R: Inter- and intrarater scoring agreement using grades 1.0 to 3.5 of the Kurtzke Expanded Disability Status Scale (EDSS). Neurology 1992, 42:859-863.

28. Marolf MV, Vaney C, Konig N, Schenj T, Prosiegel M: Evaluation of disability in multiple sclerosis patients: a comparative study of the functional independence measure, the extended barthel index and the expanded disability status scale. Clin Rehabil 1996, 10:309-313.

29. Sharrack B, Hughes R, Soudain S, Dunn G: The psychometric properties of clinical rating scales used in multiple sclerosis. Brain J Neurol 1999 122:141-159.

30. Willoughby EW, Paty DW: Scales for rating impairment in multiple sclerosis: a critique. Neurology 1988, 38:1793-1798.

31. Amato MP, Ponziani G: Quantification of impairment in MS: discussion of the scales in use. Mult Scler 1999, 5:216-219.

32. Hobart J, Freeman J, Thompson A: Kurtzke scales revisted: the application of psychometric methods to clinical intuition. Brain 2000, 123:1027-1040.

33. Multiple IFNB, Sclerosis Study Group: Interferon beta-1b is effective in relapsing-remitting multiple sclerosis. I. Clinical results of a multicenter, randomized, double-blind, placebo-controlled trial. Neurology 1993, 43:655-661.

34. PRIMS (Prevention of Relapses and Disability by Interferon beta-1a Subcutaneously in Multiple Sclerosis) Study Group: Randomised double-blind placebo-controlled study of interferon beta-1a in relapsing/ remitting multiple sclerosis. Lancet 1998, 352:1498-1504.

35. Jacobs LD, Cookfair DL, Rudick RA, Herndon RM, Richert JR, Salazar AM, Fischer JS, Goodkin DE, Granger CV, Simon JH, Alam JJ, Bartoszak DM, Bourdette DN, Braiman J, Brownscheidle CM, Coats ME, Cohan SL, Dougherty DS, Kinkel RP, Mass MK, Munschauer FE 3rd, Priore RL, Pullicino PM, Scherokman BJ, Weinstock-Guttman B, Whitham RH: Intramuscular interferon beta-1a for disease progression in relapsing multiple sclerosis. The Multiple Sclerosis Collaborative Research Group (MSCRG). Ann Neurol 1996, 39:285-294.

36. Johnson KP, Brooks BR, Cohen JA, Ford CC, Goldstein J, Lisak RP, Myers LW Panitch HS, Rose JW, Schiffer RB: Copolymer 1 reduces relapse rate and improves disability in relapsing-remitting multiple sclerosis: results of a phase III multicenter, double-blind, placebo-controlled trial. Neurology 1995, 45(7):1268-1276.

37. Paty DW, Li DK: Interferon beta-1 bis effective in relapsing-remitting multiple sclerosis. II. MRI analyses results of a multicenter, randomized, double-blind, placebo-controlled trial UBCMS/MRI study group and the IFNB multiple sclerosis study group. Neurology 1993, 43:622-667.

38. Wolinsky JS, Narayana PA, Johnson KP: United-States open-label glatiramer acetate extension trial for relapsing multiple sclerosis: MRI and clinical correlates. Multiple Sclerosis Study Group and the MRI Analysis Center. Mult Scler 2001, 7:33-41.

39. Coles AJ, Compston DA, Selmaj KW, Lake SL, Moran S, Margolin DH, Norris $\mathrm{K}$, Tandon PK: Alemtuzumab vs. interferon beta-1a in early multiple sclerosis. N Engl J Med 2008, 359:1786-1801.

40. Polman CH, O'Connor PW, Havrdova E, Hutchinson M, Kappos L, Miller DH, Phillips JT, Lublin FD, Giovannoni G, Wajgt A, Toal M, Lynn F, Panzara MA, Sandrock AW, AFFIRM Investigators: A randomized, placebo-controlled trial of natalizumab for relapsing multiple sclerosis. N Engl J Med 2006 354:899-891.

41. Rudick RA, Stuart WH, Calabresi PA, Confavreux C, Galetta SL, Radue EW, Lublin FD, Weinstock-Guttman B, Wynn DR, Lynn F, Panzara MA, Sandrock AW, SENTINEL Investigators: Natalizumab plus interferon beta-1a for relapsing multiple sclerosis. N Engl J Med 2006, 354:911-923.

42. European Medicines Agency (EMA): Guideline of clinical investigation of medical products for the treatment of Multiple Sclerosis. Draft. EMA/ 
CHMP/771815/2011, Rev 2,20 September 2012. http://www.ema.europa.eu/ docs/en_GB/document_library/Scientific_guideline/2012/10/WC500133438.pdf.

43. Amato MP, Groppi C, Siracusa G, Fratiglioni: Inter and intra-observer reliability in Kurtzke scoring systems in multiple sclerosis. Ital J Neurol Sci 1987, Supplement 6:129-131

44. Amato MP, Fratiglioni L, Groppi C, Siracusa G, Amaducci L: Interrater reliability in assessing functional systems and disability on the Kurtzke scale in multiple sclerosis. Arch Neurol 1988, 45:746-748.

45. Amato MP, Portaccio E: Clinical outcome measures in multiple sclerosis. J Neurol Sci 2007, 259:118-122.

46. Ebers GC, Heigenhauser L, Daumer M, Lederer C, Noseworthy JH: Disability as an outcome in MS clinical trials. Neurology 2008, 71:624-631

47. Brosseau $L$, Wolfson $C$ : The inter-rater reliability and construct validity of the functional independence measure for multiple sclerosis subjects. Clin Rehabil 1994, 8:107-115.

48. Rothwell PM, McDowell Z, Wong CK, Dorman PJ: Doctors and patients don't agree: cross sectional study of patient's and doctors' perceptions and assessments of disability in multiple sclerosis. Br Med J 1997, 314:1580-1583.

49. Schwid SR, Goodman AD, Mattson DH, Mihai C, Donohoe KM, Petrie MD, Scheid EA, Dudman JT, McDermott MP: The measurement of ambulatory impairment in multiple sclerosis. Neurology 1997, 49:1419-1424.

50. Cohen RA, Kessler HR, Fischer M: The Extended Disability Status Scale (EDSS) as a predictor of impairments of functional activities of daily living in multiple-sclerosis. J Neurol Sci 1993, 115:132-135.

51. Gaspari M, Roveda G, Scandellari C, Stecchi S: An expert system for the evaluation of EDSS in multiple sclerosis. Artif Intell Med 2002, 25:187-210.

52. Cohen JA, Fischer JS, Bolibrush DM, Jak AJ, Kniker JE, Mertz LA, Skaramagas $\Pi$, Cutter GR: Intrarater and interrater reliability of the MS functional composite outcome measure. Neurology 2000, 54:802-806.

53. Hohol MJ, Orav EJ, Weiner HL: Disease steps in multiple-sclerosis a simple approach to evaluate disease progression. Neurology 1995, 45:251-255.

54. Hutchinson J, Hutchinson M: The functional limitations profile may be a valid, reliable and sensitive measure of disability in multiple-sclerosis. J Neurol 1995, 242:650-657.

55. Schwid SR, Goodman AD, Apatoff BR, Coyle PK, Jacobs LD, Krupp LB, Miller AE, Wende KE, Brownscheidle CM, New York State Multiple Sclero: Are quantitative functional measures more sensitive to worsening MS than traditional measures? Neurology 2000, 55:1901-1903.

56. Vaney C, Blaurock H, Gattlen B, Meisels C: Assessing mobility in multiple sclerosis using the rivermead mobility index and gait speed. Clin Rehabil 1996, 10:216-226.

57. Koziol JA, Frutos A, Sipe JC, Romine JS, Beutler E: A comparison of two neurologic scoring instruments for multiple sclerosis. J Neurol 1996, 243:209-213.

58. Hohol MJ, Orav EJ, Weiner HL: Disease steps in multiple sclerosis: a longitudinal study comparing disease steps and EDSS to evaluate disease progression. Mult Scler 1999, 5:349-354.

59. Ravnborg M, Blinkenberg M, Sellebjerg F, Ballegaard M, Larsen SH, Sørensen PS: Responsiveness of the multiple sclerosis impairment scale in comparison with the expanded disability status scale. Mult Scler 2005, 11:81-84.

60. Barker-Collo SL: Quality of life in multiple sclerosis: does informationprocessing speed have an independent effect? Arch Clin Neuropsychol 2006, 21:167-174

61. Hyland M, Rudick RA: Challenges to clinical trials in multiple sclerosis: outcome measures in the era of disease-modifying drugs. Curr Opin Neurol 2011, 24:255-26.

62. Drulovic J, Riise T, Nortvedt M, Pekmezovic T, Manigoda: Self-rated physical health predicts change in disability in multiple sclerosis. Mult Scler 2008, 14:999-1002.

63. Fisk JD, Brown MG, Sketris IS, Metz LM, Murray TJ, Stadnyk KJ: A comparison of health utility measures for the evaluation of multiple sclerosis treatments. J Neurol Neurosurg Psychiatry 2005, 76:58-63.

64. Twork S, Wiesmeth S, Spindler M, Wirtz M, Schipper S, Pöhlau D, Klewer J, Kugler J: Disability status and quality of life in multiple sclerosis: non-linearity of the Expanded Disability Status Scale (EDSS). Health Qual Life Outcomes 2010, 8:55.

65. Healy B, Chitnis T, Engler D: Improving power to dect disease progression in multiple sclerosis through alternative analysis strategies. J Neurol 2011, 258:1812-1819.
66. Goodkin DE: EDSS reliability. Neurology 1991, 41:322.

67. Brochet B, Deloire MS, Bonnet M, Salort-Campana E, Ouallet JC, Petry KG, Dousset V: Should SDMT substitute for PASAT in MSFC? A 5-year longitudinal study. Mult Scler J 2008, 14:1242-1249.

68. Kalkers NF, Bergers L, de Groot V, Lazeron RH, van Walderveen MA, Uitdehaag BM, Polman $\mathrm{CH}$, Barkhof F: Concurrent validity of the MS functional composite using MRI as a biological disease marker. Neurology 2001, 56:215-219.

69. Hoogervorst EL, Kalkers NF, Cutter GR, Uitdehaag BM, Polman CH: The patient's perception of a (reliable) change in the Multiple Sclerosis Functional Composite. Mult Scler 2004, 10:55-60.

70. Miller DM, Rudick RA, Cutter G, Baier M, Fischer JS: Clinical significance of the multiple sclerosis functional composite: relationship to patient-reported quality of life. Arch Neurol 2000, 57:1319-1324.

71. Ozakbas S, Cagiran I, Ormeci B, Idiman E: Correlations between multiple sclerosis functional composite, expanded disability status scale and health-related quality of life during and after treatment of relapses in patients with multiple sclerosis. J Neurol Sci 2004, 218:3-7.

72. Honarmand K, Akbar N, Kou N, Feinstein A: Predicting employment status in multiple sclerosis patients: the utility of the MS functional composite. J Neurol 2011, 258:244-249.

73. Cohen JA, Reingold SC, Polman CH, Wolinsky JS: Disability outcome measures in multiple sclerosis clinical trials: current status and future prospects. Lancet Neurol 2012, 11:467-476.

74. Rudick RA, Cutter G, Reinold S: The multiple sclerosis functional composite: a new clinical outcome measure for multiple sclerosis. Mult Scler 2002, 8:359-365.

75. Cohen JA, Cutter GR, Fischer JS, Goodman AD, Heidenreich FR, Jak AJ, Kniker JE, Kooijmans MF, Lull JM, Sandrock AW, Simon JH, Simonian NA, Whitaker JN: Use of the multiple sclerosis functional composite as an outcome measure in a phase 3 clinical trial. Arch Neurol 2001, 58:961-967.

76. Hoogervorst EL, Kalkers NF, Uitdehaag BM, Polman CH: A study validating changes in the multiple sclerosis functional composite. Arch Neurol 2002, 59:113-116.

77. Pascual AM, Boscá I, Coret F, Escutia M, Bernat A, Casanova B: Evaluation of response of multiple sclerosis (MS) relapse to oral high-dose methylprednisolone: usefulness of MS functional composite and Expanded Disability Status Scale. Eur J Neurol 2008, 15:284-288.

78. Kalkers NF, de Groot V, Lazeron RH, Killestein J, Adèr HJ, Barkhof F, Lankhorst GJ, Polman $\mathrm{CH}$ : MS functional composite - relation to disease phenotype and disability strata. Neurology 2000, 54:1233-1239.

79. Miller DM, Cohen JA, Kooijmans M, Tsao E, Cutter G, Baier M: Change in clinician-assessed measures of multiple sclerosis and subject-reported quality of life: results from the IMPACT study. Mult Scler 2006, 12:180-186.

80. Rosti-Otajarvi $E$, Hämäläinen $P$, Koivisto $K$, Hokkanen L: The reliability of the MSFC and its components. Acta Neurol Scand 2008, 117:421-427.

81. Schwid SR, Goodman AD, McDermott MP, Bever CF, Cook SD: Quantitative functional measures in MS: What is a reliable change? Neurology 2002, 58:1294-1296.

82. Bosma LVAE, Kragt JJ, Brieva L, Khaleeli Z, Montalban X, Polman CH, Thompson AJ, Tintoré $M$, Uitdehaag BM: Progression on the multiple sclerosis functional composite in multiple sclerosis: what is the optimal cut-off for the three components? Mult Scler J 2010, 16:862-867.

83. Solari A, Radice D, Manneschi L, Motti L, Montanari E: The multiple sclerosis functional composite: different practice effects in the three test components. J Neurol Sci 2005, 228:71-74.

84. Ozakbas S, Ormeci B, Idiman E: Utilization of the multiple sclerosis functional composite in follow-up: relationship to disease phenotype, disability and treatment strategies. J Neurol Sci 2005, 232:65-69.

85. Patzold T, Schwengelbeck M, Ossege LM, Malin JP, Sindern E: Changes of the MS functional composite and EDSS during and after treatment of relapses with methylprednisolone in patients with multiple sclerosis. Acta Neurol Scand 2002, 105:164-168.

86. Kragt JJ, van der Linden FA, Nielsen JM, Uitdehaag BM, Polman CH: Clinical impact of $20 \%$ worsening on timed 25 -foot walk and 9-hole peg test in multiple sclerosis. Mult Scler 2006, 12:594-598.

87. Coo H, Hopman WM, Edgar CM, McBride EV, Brunet DG: The Paced Auditory Serial Addition Test: to what extent is it performed as instructed, and is it associated with disease course? Mult Scler 2005, 11:85-89.

88. Fox RJ, Lee JC, Rudick RA: Optimal reference population for the multiple sclerosis functional composite. Mult Scler 2007, 13:909-914. 
89. Kaufman $\mathrm{M}$, Moyer $\mathrm{D}$, Norton J: The significant change for the timed 25 -foot walk in the multiple sclerosis functional composite. Mult Scler 2000, 6:286-290.

90. Kragt JJ, Nielsen IM, van der Linden FA, Uitdehaag BM, Polman CH: How similar are commonly combined criteria for EDSS progression in multiple sclerosis? Mult Scler 2006, 12:782-786.

doi:10.1186/1471-2377-14-58

Cite this article as: Meyer-Moock et al:: Systematic literature review and validity evaluation of the Expanded Disability Status Scale (EDSS) and the Multiple Sclerosis Functional Composite (MSFC) in patients with multiple sclerosis. BMC Neurology 2014 14:58.

\section{Submit your next manuscript to BioMed Central and take full advantage of:}

- Convenient online submission

- Thorough peer review

- No space constraints or color figure charges

- Immediate publication on acceptance

- Inclusion in PubMed, CAS, Scopus and Google Scholar

- Research which is freely available for redistribution 